https://helda.helsinki.fi

\title{
Effect of hypoxemia on fetal ventricular deformation in a chronically instrumented sheep model
}

\section{Bhide, Amarnath}

2017-05

Bhide , A , Räsänen , J , Huhta , H , Junno , J , Erkinaro , T , Ohtonen , P , Haapsamo , M \& Acharya , G 2017 , ' Effect of hypoxemia on fetal ventricular deformation in a chronically instrumented sheep model ' , Ultrasound in Medicine \& Biology , vol. 43 , no. 5 , pp. 967-973 . https://doi.org/10.1016/j.ultrasmedbio.2017.01.010

http://hdl.handle.net/10138/313130

https://doi.org/10.1016/j.ultrasmedbio.2017.01.010

cc_by_nc_nd

acceptedVersion

Downloaded from Helda, University of Helsinki institutional repository.

This is an electronic reprint of the original article.

This reprint may differ from the original in pagination and typographic detail.

Please cite the original version. 
The effect of hypoxemia and metabolic acidemia on fetal ventricular

2 deformation in a chronically instrumented sheep model

3

4 Amarnath Bhide ${ }^{1}$, Juha Rasanen ${ }^{2,3,4}$, Heikki Huhta ${ }^{4}$, Juulia Junno ${ }^{4}$, Tiina Erkinaro ${ }^{5}$,

5 Pasi Ohtonen ${ }^{6}$, Mervi Haapsamo $^{7}$, Ganesh Acharya ${ }^{1,8}$

6

7 Women's Health \& Perinatal Research Group, Department of Clinical Medicine, UiT-

8 The Arctic University of Norway, Tromsø, Norway (1),

9 Department of Obstetrics and Gynecology, Kuopio University Hospital and

10 University of Eastern Finland, Kuopio, Finland (2),

11 Department of Obstetrics and Gynecology, Helsinki University Hospital, Helsinki,

12 Finland (3),

13 Department of Obstetrics and Gynecology (4), Anaesthesiology (5) and Statistics (6),

14 Oulu University Hospital, Oulu, Finland.

15 Department of Obstetrics and Gynecology, Lapland Central Hospital, Finland (7).

16 Department of Clinical Science, Intervention and Technology (CLINTEC),

17 Karolinska Institutet, Stockholm, Sweden (8)

18

19

20

21 Address for correspondence:

22 Dr. Amar Bhide, MD, FRCOG

23 Fetal Medicine Unit

$244^{\text {th }}$ Floor, Lanesborough Wing

25 St. George's Hospital, Blackshaw Road

26 SW17 OQT

27 United Kingdom

28 Tel: +4420 87250080

29 Fax: +44 2087250079

30 e-mail: abhide@sgul.ac.uk

31

32 Running title: Hypoxemia and myocardial strainventricular deformation

33 in fetal sheep model 


\footnotetext{
1 Abstract

2 We hypothesized that in a-near-term sheep pregnancy fetuses hypoxaemia changes myocardial function that is detectable byareis reflected in altered ventricular deformation on speckle-tracking echocardiography. Fetuses were instrumented in 21 pregnant sheep. After 4-day recovery, fetal cardiac function was assessed by speckletracking echocardiography at baseline, after 30 and 120 minutes of induced fetal

7 hypoxemia and following its reversal. Left (LV) and right ventricular (RV) cardiac

8 outputs, myocardial strains were measured. Baseline mean (SD) LV and RV global

9 longitudinal strains were $-18.7 \%$ (3.8) and $-14.3 \%$ (5.3). Baseline RV global

10 longitudinal and circumferential strains-deformations were lower-lesser $(p=0.016$

11 and $p<0.005)$ c Compared to $\operatorname{LV} \underline{(p=0.016 \text { and } p<0.005)}$. LV, but not RV global

12 longitudinal strain reduced $(\mathrm{p}=0.003)$ compared to baseline with hypoxemia.

13 Circumferential and radial strains did not show significant changes. In near-term

14 sheep fetus, LV global longitudinal and circumferential strains are more negative

15 compared to RV. Acute hypoxemia leads to LV rather than RV dysfunction as 16 demonstrated by decreased deformation.

17

18 Word count: $\mathbf{1 4 9} \underline{\underline{148}}$

19

20 Keywords - Speckle tracking echocardiography; hypoxemia; sheep model 
Introduction -

Fetal cardiovascular protective response to moderate isocapnic

hypoxiahypoxaemia involves chemoreflex, endocrine and local components. Acute fetal hypoxemia is associated with increased blood flow to the myocardium, brain and adrenal glands, but the fetal autonomic response to hypoxemia varies by gestational age (Iwamoto, et al. 1989). At 0.6-0.7 gestation in fetal sheep (87-102 days), the arterial blood pressure (BP) does not change significantly and fetal heart rate may remain unchanged or increase slightly (Iwamoto, et al. 1989), whereas at 0.9 gestation

9 vagally mediated bradycardia and a rise of BP is observed (Giussani, et al. 1993).

10 Hemodynamic changes related to acute and chronic hypoxemia in sheep fetuses have 11 been well described (Carter 2015, Jensen, et al. 1999, Rudolph 1985). Chronic 12 hypoxemia without acidemia does not affect the fetal cardiac output (Block, et al. 13 1990): Band blood flow to the placenta, carcass, kidney, and spleen are maintained remain unchanged-with chronic hypoxaemia until fetal acidosis develops fwithout acidaemia), but it decreases with fetal acidemianademia (Jensen, et al. 1999). We have-previously reported that acute hypoxemia in near-term fetal sheep leads to an 17 increase in the pulmonary arterial vascular impedance, as well as an increase in the 18 right ventricular cardiac output (Mäkikallio, et al. 2006). Peak myocardial velocities 19 measured by tissue Doppler technique appear to decrease during hypoxemia/acidemia especially during the isovolumic periods of cardiac cycle when tissue Doppler technique is used-(Acharya, et al. 2008). However, changes in myocardial strain that 22 may occur during fetal hypoxemia have not been elucidated. Two-dimensional (2-D) 23 strain imaging uses standard B-mode images and speckle--tracking for the evaluation 24 of myocardial deformation. Lagrangian strain is defined as the instantaneous 25 lengthening or shortening compared to the initial muscle fiber length, which, in the 26 myocardium, is commonly determined by the end of diastole (D'Hooge, et al. 2000).

27 The relative independence of the angle of ultrasound beam and direction of movement 28 makes this technique less prone to errors. Speckle tracking echocardiography is still a 29 research tool, and thitse placevalue in clinical practice is being debated at 30 present(Huang and Orde 2013, Orde, et al. 2016, Tanaka and Hirata 2016).- This 31 technique has been used to evaluate cardiac function in normal fetuses (Kapusta, et al. 2012), those of diabetic mothers (Kulkarni, et al. 2016), fetuses with twin to twin 33 transfusion syndrome and those with congenital diaphragmatic hernia (Van Mieghem, 34 et al. 2011). To our knowledge, rResponse of fetal eardiac functiomyocardiuma to 
hypoxaemia has not been evaluated before-using speckle--tracking echocardiography

has not been reported before.

The present experiment on near-term fetal sheep was designed to test the

4 hypothesis that a decrease in fetal oxygenation leads to compensatory changes in the

myocardial function that can be detected by 2-D speckle_-tracking echocardiography.

Specifically, wWe aimed to Theevaluateasked two questions in this study: 1) are

whether potential uses of -left and right ventricular deformations similar in

normoxemic conditions and 2) are their responses to prolonged hypoxemia different?

this technique has a potential is to develop be used as a new and more sensitive tests

to detect myocardial dysfunction caused by fetal hypoxaemia, so that surveillance of

eompromised fetuses and appropriate interventions are possiblecould be improved.

12

13 Material and methods

All experiments were performed in accordance with the 'European

15 Convention for the Protection of Vertebrate Animals used for Experimental and Other

16 Scientific Purposes' (Council of Europe 1986) and the European Union Directive ETS

17 123 (1997). The Animal Care and Use Committee of the University of Oulu approved

18 the study protocol.

Animal preparation

Data from 21 chronically instrumented pregnant sheep were used for this

21 report. Mean (SD)-weight of the ewes and the fetuses was 53.9 (SD:8.1) kg and 2401 22 (256) g, respectively.

23 Surgery was performed at 115-129 gestational days (term 145 days). Ewes

24 were fasted overnight and pre-medicated with intramuscular ketamine $(2 \mathrm{mg} / \mathrm{kg})$ and 25 midazolam $(0.2 \mathrm{mg} / \mathrm{kg})$. The maternal external jugular vein was cannulated and

26 Ringer's lactate solution was infused at a rate of $200 \mathrm{ml} / \mathrm{h}$. General anesthesia was

27 induced with intravenous Propofol (4-7 mg/kg) and maintained with Isoflurane (1.5-

$282.5 \%$ ) in an oxygen-air mixture delivered via an endotracheal tube. Intravenous

29 boluses of fentanyl $(0.05-0.15 \mathrm{mg})$ were administered as required.

30 A laparotomy was performed under general anesthesia and endotracheal 31 intubation. The fetal head and neck were delivered through a small uterine incision.

32 Catheters were introduced in the internal jugular vein and the carotid artery to allow 33 access to arterial and venous circulations, and to collect blood samples. 
A small left lateral thoracotomy was performed at the level of $3^{\text {rd }}$ intercostal space and the-fetal ductus arteriosus was identified and dissected. A $4 \mathrm{~mm}$ ultrasonic transit-time flow probe was secured around the vessel and tunneled outside for the 4 measurement of ductus arteriosus blood flow. Thoracotomy was closed. 5 Electrocardiogram (ECG) leads were placed subcutaneously to obtain fetal ECG. A 6 catheter was anchored to the fetal skin to measure intra amniotic pressure. After the 7 replacement of amniotic fluid by $0.9 \%$ warm saline and closure of the surgical 8 wounds, all catheters and probes were tunneled subcutaneously and exteriorized 9 through a small skin incision in the ewe's flank. Postoperative analgesia was provided 10 with a fentanyl patch $(50 \mathrm{mcg} / \mathrm{h})$ attached to the ewe's tail, with additional 11 intramuscular injections of fentanyl 1.5 to $2 \mathrm{mg} / \mathrm{kg}$ twice daily.

After a 4-day recovery, general anesthesia was induced again as described 13 above. A 16-gauge polyurethane catheter was inserted into the maternal descending 14 aorta through a femoral artery. The ewe was placed supine with a right lateral tilt and 15 allowed to stabilize for $30 \mathrm{~min}$ before the baseline measurements. Thereafter, 16 maternal and fetal hypoxemia was induced by replacing inhaled oxygen with medical 17 air in the re-breathing circuit to reach maternal oxyhemoglobin saturation level of 75$1880 \%$. Hypoxemia phase data were obtained at 30 minutes and 120 minutes after 19 reaching desired maternal saturation level. After the data collection for the last 20 hypoxemia phase was completed, oxygen was substituted, and re-breathing 21 discontinued to allow recovery from hypoxemia, and recovery phase data was 22 obtained 15 minutes after maternal normoxemia was established. Fetal heart rate was 23 monitored with a cardiotachometer triggered from the arterial pressure waves. Fetal 24 arterial blood pressure was referenced to amniotic fluid pressure. Fetal blood samples 25 were obtained to measure the acid-base status, and blood gases at the end of each 26 phase. At the end of the experiment, the animals were euthanized with an intravenous 27 overdose $(1.0 \mathrm{mg} / \mathrm{kg})$ of pentobarbital sodium. Fetal weight was recorded. Twodimensional speckle tracking echocardiography Fetal

30 echocardiography was performed using Vivid 7 ultrasound system (GE medical 31 systems, Horten, Norway) with a $10-\mathrm{MHz}$ phased-array transducer $7 \mathrm{~S}$ phased array 32 probe-to obtain 2-D gray-scale images with a high frame-rate. Cine-loop images of 33 four-chamber view and short-axis view at the level of papillary muscles were 34 obtained by a single investigator (JR). The imaging depth was $5-10 \mathrm{~cm}$ and the 
mechanical index (MI) and thermal index (TI) were kept below 1.5 and 1.0,

respectively. Two stable well-defined consecutive cardiac cycles from each view were used for speckle tracking analysis. The scan-line digital data for these images were

4 processed using acoustic-tracking software (EchoPAC, GE medical systems, Horten,

5 Norway), allowing off-line semi-automated analysis of speckle-based strain.

The off-line analysis was performed by a single operator (AB) who was

7 blinded to the fetal arterial blood gas values and hemodynamic data. Endocardial

8 surface was manually traced at the end-systolic frame, and an automated tracking

9 algorithm outlined the myocardium in successive frames throughout the cardiac cycle

10 (Figure 1). Tracking quality was verified automatically for each segment. Manual

11 adjustment of the region of interest was performed if necessary. Myocardial global

12 longitudinal strain was measured for left and the right ventricles on a four-chamber

13 view. These measurements were repeated in another cardiac cycle from the second

14 stored cine-loop of the same fetus. Mean of these two measurements were used for

15 data analysis. Interventricular septum was not excluded while measurement of right

16 ventricularthe RV global longitudinal strain was performed. Global circumferential

17 and radial strains for the left and the right ventricle (Hayabuchi, et al. 2015) were

18 calculated from the short-axis view at the level of the papillary muscles_(Figure 2). An

19 average of segmental values was calculated to obtain global values.

obtained at the level of aortic and pulmonary valves from the left and the right ventricular outflow tracts-keeping the angle of insonation close to zero degrees

24 (always $<15$ degrees), and the mean velocities were determined (mean velocity $=$ 25 time-velocity integral $\mathrm{x}$ heart rate). Inner diameters of the aortic and pulmonary

26 valves were measured using a B-mode cine loop images keeping the insonation angle

27 perpendicular to the vessels as far as possible (Kiserud, et al. 2006). An average of

28 three measurements was used for calculating cardiac outputs. The left (LVCO) and

29 the right ventricular cardiac outputs (RVCO) were computed separately as: cardiac

30 output $(\mathrm{CO})=$ mean velocity $\times 3.14$ (diameter of the outflow tract $/ 2)^{2}$. The combined

31 cardiac output (CCO) was calculated as the sum of LVCO and RVCO.

32 
2 volume blood flow was calculated as the difference between the RVCO and the ductus arteriosus volume blood flow. Doppler blood flow velocity waveforms were obtained from the right pulmonary artery (RPA) as described previously (Rasanen, et

5 al. 1996). Pulsatility index (PI) was calculated as: (peak systolic velocity - end-

6 diastolic velocity)/time-averaged maximum velocity(Deane 2000) as a surrogate for

7 pulmonary arterial vascular impedance.

\section{Statistical analysis}

Data were expressed as mean and standard deviation (SD) unless stated 11 otherwise. Linear Mixed Model (LMM) was used for repeatedly measured data. If 12 LMM showed a significant difference between measurement points $\left(\mathrm{P}_{\text {time }}<0.05\right)$, then 13 a pairwise comparison between relevant points was performed. Paired samples t-test 14 was used to compare LV and RV global longitudinal, circumferential and radial 15 strains. Mean differences with $95 \%$ confidence intervals $(95 \% \mathrm{CI})$ are presented for 16 paired samples t-test. Statistical analyses were performed using SPSS (IBM Corp. 17 Released 2011. IBM SPSS Statistics for Windows, Version 20.0. Armonk, NY: IBM 18 Corp.) and SAS (version 9.3. SAS Institute Inc., Cary, NC, USA). Two-tailed p value $19<0.05$ was considered statistically significant.

\section{Results} and during recovery phase it returned back to baseline level (Table 1). Fetal $\mathrm{pH}$

\section{Blood gas values and hemodynamic data}

As expected, mMaternal hypoxemia led to a significant reduction in fetal $\mathrm{pO}_{2}$, decreased_significantly at 120-minute hypoxemia phase_significantly and remained significantly lower during recovery phase than at baseline. In addition, fetal lactate

31 level was significantly higher during hypoxemia and recovery phases than at baseline.

32 Fetal $\mathrm{pCO}_{2}$ did not change during the experiment. Hypoxemia decreased fetal arterial

33 blood pressures significantly (Table 1). Fetal heart rate was significantly lower at the

34 recovery phase as compared to baseline and hypoxemia phases. During hypoxemia, 
1 there was a significant increase in fetal RPA PI values and a decrease in LVCO.

2 Pulmonary blood flow decreased with hypoxemia compared to the baseline, but the

3 reduction did not reach statistical significance. Fetal RVCO and CCO remained stable

4 during the entire experiment (Table 1).

5

$6 \quad 2-D$ strain data

Ultrasound recordings were obtained at a mean frame rate of 167 (Range: 126-

8 235) frames/sec. At baseline, there was significantly more deformation in the LV

9 global longitudinal $(p=0.016)$ and circumferential $(p<0.005)$ strains than in the

10 corresponding parameters of the RV (Table 2). Hypoxemia at 30 and 120 minutes led

11 to a significant reduction (less deformation) in the global longitudinal strain of the

$12 \mathrm{LV}$, while the global circumferential and radial strains were not affected by fetal

13 hypoxemia (Table 2, Figure $\underline{3} z$ ). During the recovery period, LV global longitudinal

14 strain returned back to baseline level. Right ventricular global longitudinal,

15 circumferential and radial strains did not change statistically significantly. Baseline

16 left ventricular strain rate was significantly higher than the right $(p=0.003)$. during

17 the experimentThere were no significant changes in left or right ventricular global

18 longitudinal strain rates during the experiment. (Table 2).

19

\section{Discussion}

30 The present study was designed to investigate the effects of fetal hypoxemia and metabolic acidemia on LV and RV strain formation. The experiments were done

32 in fetal sheep at 0.8 gestation that corresponds to approximately 30-32 weeks

33 gestation of human pregnancy. Blood gas values demonstrated that after 30 minutes

34 of hypo-oxygenation the fetuses were hypoxemic without any significant metabolic 
component, but prolonged hypoxemia (120 minutes) led to significant fetal metabolic acidemia. In the recovery phase, fetal oxygenation returned back to baseline level, but there was still significant metabolic acidemia. We found that at baseline there was more global longitudinal and circumferential deformation (strain) in the LV than in the RV. Fetal hypoxemia was associated with reduced LV global longitudinal strain that returned back to baseline level when fetal normoxemia was restored, even though the fetus still had a significant metabolic acidemia. Fetal hypoxemia, even with and/or metabolic acidemiaacademia, had no effect on RV strains.

A reduction in the LV global longitudinal deformation with hypoxemia may 11 be a result of reduced LV preload, direct LV myocardial dysfunction or a combination 12 of the two. It has been shown that pulmonary circulation is sensitive to fetal 13 oxygenation during the last trimester of pregnancy (Rasanen, et al. 1996), and that 14 hypoxemia leads to pulmonary vasoconstriction (Arraut, et al. 2013). Indeed, in the 15 current experiment RPA PI values increased significantly with hypoxemia suggesting 16 that impedance to pulmonary blood flow increased during hypoxemia, although the 17 reduction in the estimated pulmonary volume blood flow was not statistically 18 significant. It has been shown in a near-term sheep model of acute ductus arteriosus 19 occlusion that the fetus is unable to increase volume blood flow across the foramen 20 ovale (Tulzer, et al. 1991), thus the reduction in the LVCO is most likelymust be a 21 consequence of a drop in pulmonary volume blood flow leading to a decrease in LV 22 preload. It has been shown in human fetuses that global longitudinal strain is similar 23 in both ventricles at 20-24 weeks of gestation (Kapusta, et al. 2012). Later in 24 pregnancy LV global longitudinal strain does not change, however, corresponding RV 25 strain or deformation decreases. This is explained by an increase in the RV preload. If 26 the change in preload would be the major factor in the strain formation, we should 27 have observed an opposite finding in the LV global longitudinal strain. Therefore, our 28 results suggest that the decrease in the LV global longitudinal strain during 29 hypoxemia was caused by LV myocardial dysfunction.indicate that the direct effect of 30 hypoxemia on inherentintrinsic contractile properties of the LV is -likely responsible 31 for decreased global longitudinal strain.play a role in addition to the effect of preload 32 and afterload. 
Fetal global LV longitudinal deformation already decreased at 30-minute

2 hypoxemia phase, when significant metabolic acidemia had not yet developed. At

3 120-minute hypoxemia phase fetal $\mathrm{pO}_{2}$ was comparable to 30-minute hypoxemia

4 phase, however, a significant metabolic acidemia had developed between these two

5 time points. Interestingly, we found no further deterioration in any of the strain

6 parameters. We have previously reported that fetal LV is more susceptible to

7 hypoxemia as compared to fetal RV. However, in that study, fetal cardiac function

8 and hemodynamics were assessed by tissue Doppler and pulsed Doppler imaging,

9 rather than speckle tracking The findings of this study corroborate our previous

10 observations. We have also found that the fetal LV myocardial performance index

11 (MPI) significantly worsens with hypoxemia_(Bhide, et al. 2016), which also supports

12 the findings of this study. At recovery phase, when fetal oxygenation was returned

13 back to baseline conditions, the LV global longitudinal strain was similar to baseline

14 values, even though fetuses were still suffering from significant metabolic acidemia.

15 Furthermore, LVCO, RVCO or CCO did not show significant changes with

16 progressive metabolic acidemia. This shows that the fetal myocardial function was

17 not further deteriorated despite worsening metabolic acidemia. Our results suggest

18 that LV function appears to be more sensitive to oxygenation than metabolic acidosis.

19 Experimental intravenous infusion of lactic acid to sheep fetuses led to reduction in

20 fetal $\mathrm{pH}$, increase in the heart rate but no change in blood pressure (Hohimer and

21 Bissonnette 1991). This also suggests that lactic acid does not influence cardiac

22 function.

Di Salvo et al (Di Salvo, et al. 2005) were the first to describe fetal LV and

26 RV function using ultrasound based strain and strain rate imaging. They used

27 myocardial color Doppler imaging for quantification of strain. Doppler technology is

28 known to be angle dependent, which speckle tracking can eliminate (Biswas, et al.

29 2013). There are several software programs to assess myocardial deformation using

30 speckle tracking. However, they are not necessarily comparable. The velocity vector

31 imaging mainly tracks myocardial motion in a narrow area just underneath the

32 endocardium. In contrast, the EchoPAC automated functional imaging software tracks

33 myocardial deformation in a relatively wider area, specified by the operator (Biswas,

34 et al. 2013). 
2 Strengths and weaknesses -

At least 60-110 frames per second are recommended when imaging the adult heart (Mondillo, et al. 2011), and even higher rates are desirable to provide enough

5 frames per heart beat in the fetus (Matsui, et al. 2011). We studied the fetus at a mean

6 frame rate of $167 \mathrm{~Hz}$, and this is likely to have led to reliable results. The surgical

7 procedures may constitute a significant stress on the sheep fetuses, and it may be

8 argued that the conditions are quite different from human fetuses exposed to

9 hypoxemia. Normal arterial blood gas values at the baseline stage suggest conditions

10 close to physiologic circulatory state (Acharya, et al. 2004). The study was carried out

11 in a narrow gestational age window of 115-129 days, and may limit the validity and

12 significance outside this time period. Extrapolation of these results to human

13 pregnancy should be done cautiously. The sheep model has been extensively used for

14 research in fetal hemodynamics, and the myocardial strain curves are similar in

15 normal ovine and human pregnancy. We did not monitor cerebral blood flow during

16 the experiment and ift could be argued that the reduction in LV global longitudinal

17 strain could just reflect a drop in cerebral vascular resistance during hypoxemia.

18 Indeed, carotid artery blood pressure decreased during hypoxemia. Furthermore, it has

19 been shown that carotid artery volume blood flow increases from about $85 \mathrm{ml} / \mathrm{min}$

20 (normoxemia) to about $95-100 \mathrm{ml} / \mathrm{min}$ during isocapnic hypoxemia (Bennet, et al.

21 1998)(ref). We can estimate that there was about $24 \%$ reduction in the carotid artery

22 vascular resistance during hypoxemia. However, based on these estimations, over

$23 \quad 80 \%$ of LVCO bypasses brain circulation during prolonged hypoxemia and is affected

24 by lower body vascular resistance. Thus, we believe that reduced carotid artery

25 vascular resistance is not the main determinant of reduced LV global longitudinal

26 strain during hypoxemia. effects shown could have just as much of as much an effect

27 on the preload as on the afterload of the LV, and cerebrovascular resistance should

28 have been studied. The blood pressure was obtained by a catheter placed in the carotid

29 antery of the fetus, which. Therefore, the it is a directly reflectsion of the

30 cerebrovascular resistance. Both systolic and diastolic blood pressures showed a

31 reduction with the onset of hypoxaemia, reflecting the cerebral vasodilatation as a

32 fetal response to hypoxaemia. If hypoxemia affected only the cerebrovascular

33 resistance and not the left ventricularLV contractility, the left ventricularLV output

34 should not have changed. THowever, he LV output showed a reductiondecreased 
with hypoxaemia, anwhichd is highly suggestive of a reduction in LV contractility.

The green symbol obtained for the automatic evaluation of myocardial speckle tracking strain solution indicates the highest level of minimization of the sum of the absolute difference by the algorithm, and indicates the highest level of confidence in the speckle tracking computations and in the strain solutions.

\section{$\underline{\underline{\text { Conclusion }}}$}

7 We have shown that hypoxemia leads to changes in fetal cardiac function that 8 is reflected in altered ventricular deformation on the fetal heart function and its

9 response to hypoxemia can be evaluated using speckle-tracking echocardiography. At 10 a gestational age equivalent to 0.8 term, the global longitudinal and circumferential 11 strains are less negative in the RV as compared to the LV. Fetus responds to acute 12 hypoxemia by reduced deformation of the LV, but not the RV, and this response is 13 reversed by reversal of hypoxemia. This recovery of $L V$ fetal cardiac function is seen even in the face of worseningpresence of metabolic acidemia.

15

16 Acknowledgement: This study was funded by the Regional Health Authority of 17 Northern Norway.

18 


\section{References}

2 Acharya G, Erkinaro T, Makikallio K, Lappalainen T, Rasanen J. Relationships among Doppler-derived umbilical artery absolute velocities, cardiac function, and placental volume blood flow and resistance in fetal sheep. American journal of physiology. Heart and circulatory physiology 2004; 286:H1266-72.

Acharya G, Rasanen J, Makikallio K, Erkinaro T, Kavasmaa T, Haapsamo M,

Mertens L, Huhta JC. Metabolic acidosis decreases fetal myocardial isovolumic velocities in a chronic sheep model of increased placental vascular resistance. American journal of physiology. Heart and circulatory physiology 2008; 294:H498-504.

Arraut AM, Frias AE, Hobbs TR, McEvoy C, Spindel ER, Rasanen J. Fetal pulmonary arterial vascular impedance reflects changes in fetal oxygenation at near-term gestation in a nonhuman primate model. Reprod Sci 2013; 20:33-8.

Bennet L, Peebles DM, Edwards AD, Rios A, Hanson MA. The cerebral hemodynamic response to asphyxia and hypoxia in the near-term fetal sheep as measured by near infrared spectroscopy. Pediatric research 1998; 44:951-7.

Bhide A, Vuolteenaho O, Haapsamo M, Erkinaro T, Rasanen J, Acharya G. Effect of Hypoxemia with or without Increased Placental Vascular Resistance on Fetal Left and Right Ventricular Myocardial Performance Index in Chronically Instrumented Sheep. Ultrasound in medicine \& biology 2016; 42:2589-98.

Biswas M, Sudhakar S, Nanda NC, Buckberg G, Pradhan M, Roomi AU, Gorissen W, Houle H. Two- and three-dimensional speckle tracking echocardiography: clinical applications and future directions. Echocardiography 2013; 30:88-105.

Block BS, Schlafer DH, Wentworth RA, Kreitzer LA, Nathanielsz PW. Intrauterine

Carter AM. Placental Gas Exchange and the Oxygen Supply to the Fetus. Compr Physiol 2015; 5:1381-403.

D'Hooge J, Heimdal A, Jamal F, Kukulski T, Bijnens B, Rademakers F, Hatle L, Suetens $\mathrm{P}$, Sutherland GR. Regional strain and strain rate measurements by cardiac ultrasound: principles, implementation and limitations. European journal of echocardiography : the journal of the Working Group on Echocardiography of the European Society of Cardiology 2000; 1:154-70. 
Deane C. Doppler Ultrasound:priciples and practice, In: Niclaides K, Rizzo G, Hecher K., ed. Placental and fetal Doppler. London: The Parthenon Publishing Group, 2000. 22.

Di Salvo G, Russo MG, Paladini D, Pacileo G, Felicetti M, Ricci C, Cardaropoli D, Palma M, Caso P, Calabro R. Quantification of regional left and right

Giussani DA, Spencer JA, Moore PJ, Bennet L, Hanson MA. Afferent and efferent ventricular longitudinal function in 75 normal fetuses using ultrasound-based strain rate and strain imaging. Ultrasound in medicine \& biology 2005; 31:1159-62. components of the cardiovascular reflex responses to acute hypoxia in term fetal sheep. The Journal of physiology 1993; 461:431-49.

Hayabuchi Y, Sakata M, Kagami S. Right ventricular myocardial deformation patterns in children with congenital heart disease associated with right ventricular pressure overload. Eur Heart J Cardiovasc Imaging 2015; 16:8909.

Hohimer AR, Bissonnette JM. Vascular lactic acid infusions do not alter the incidence of fetal breathing movements or their inhibition by acute hypoxemia. Pediatric research 1991; 29:483-6.

Huang SJ, Orde S. From speckle tracking echocardiography to torsion: research tool today, clinical practice tomorrow. Curr Opin Crit Care 2013; 19:250-7.

Iwamoto HS, Kaufman T, Keil LC, Rudolph AM. Responses to acute hypoxemia in fetal sheep at 0.6-0.7 gestation. The American journal of physiology 1989; 256:H613-20.

Jensen A, Garnier Y, Berger R. Dynamics of fetal circulatory responses to hypoxia and asphyxia. European journal of obstetrics, gynecology, and reproductive biology 1999; 84:155-72.

Kapusta L, Mainzer G, Weiner Z, Deutsch L, Khoury A, Haddad S, Lorber A. Second trimester ultrasound: reference values for two-dimensional speckle trackingderived longitudinal strain, strain rate and time to peak deformation of the fetal heart. Journal of the American Society of Echocardiography : official publication of the American Society of Echocardiography 2012; 25:1333-41.

Kiserud T, Ebbing C, Kessler J, Rasmussen S. Fetal cardiac output, distribution to the placenta and impact of placental compromise. Ultrasound in obstetrics \& 
gynecology : the official journal of the International Society of Ultrasound in Obstetrics and Gynecology 2006; 28:126-36.

Kulkarni A, Li L, Craft M, Nanda M, Lorenzo JM, Danford D, Kutty S. Fetal Myocardial Deformation in Maternal Diabetes Mellitus and Obesity. Ultrasound in obstetrics \& gynecology : the official journal of the International Society of Ultrasound in Obstetrics and Gynecology 2016.

Mäkikallio K, Erkinaro T, Niemi N, Kavasmaa T, Acharya G, Päkkilä M, Räsänen J. Fetal oxygenation and Doppler ultrasonography of cardiovascular hemodynamics in a chronic near-term sheep model. American journal of obstetrics and gynecology 2006; 194:542-50.

Matsui H, Germanakis I, Kulinskaya E, Gardiner HM. Temporal and spatial performance of vector velocity imaging in the human fetal heart. Ultrasound in obstetrics \& gynecology : the official journal of the International Society of Ultrasound in Obstetrics and Gynecology 2011; 37:150-7.

Mondillo S, Galderisi M, Mele D, Cameli M, Lomoriello VS, Zacà V, Ballo P, D'Andrea A, Muraru D, Losi M, Agricola E, D'Errico A, Buralli S, Sciomer S, Nistri S, Badano L, Echocardiography Study Group Of The Italian Society Of Cardiology (Rome Ia. Speckle-tracking echocardiography: a new technique for assessing myocardial function. Journal of ultrasound in medicine : official journal of the American Institute of Ultrasound in Medicine 2011; 30:71-83.

Orde S, Huang SJ, McLean AS. Speckle tracking echocardiography in the critically ill: enticing research with minimal clinical practicality or the answer to noninvasive cardiac assessment? Anaesth Intensive Care 2016; 44:542-51.

Rasanen J, Wood DC, Weiner S, Ludomirski A, Huhta JC. Role of the pulmonary circulation in the distribution of human fetal cardiac output during the second half of pregnancy. Circulation 1996; 94:1068-73.

Rudolph AM. Distribution and regulation of blood flow in the fetal and neonatal lamb. Circ Res 1985; 57:811-21.

Tanaka H, Hirata K. Is speckle tracking actually helpful for cardiac resynchronization therapy? J Echocardiogr 2016; 14:53-60.

Tulzer G, Gudmundsson S, Rotondo KM, Wood DC, Yoon GY, Huhta JC. Acute fetal ductal occlusion in lambs. American journal of obstetrics and gynecology $1991 ; 165: 775-8$. 
1 Van Mieghem T, Deprest J, Verhaeghe J. Fetal and maternal hemodynamics in

2 pregnancy: new insights in the cardiovascular adaptation to uncomplicated

3 pregnancy, twin-to-twin transfusion syndrome and congenital diaphragmatic 4 hernia. Facts Views Vis Obgyn 2011; 3:205-13.

5

6 


\section{$1 \quad$ Legend to figures}

2 Figure 1. Automated tracking algorithm outlining the myocardium and calculation of 3 global strain and strain rate using Echopac software.

4

5 Figure 2. Automated tracking algorithm outlining the myocardium and calculation of

6 right ventricular global circumferential strain using Echopac software.

7

8 Figure $3 z$. Global left (solid lines) and right ventricular (dotted line) longitudinal 9 strain with hypoxemia and recovery 
1 The effect of hypoxemia on fetal ventricular deformation in a chronically

2 instrumented sheep model

3

4 Amarnath Bhide ${ }^{1}$, Juha Rasanen ${ }^{2,3,4}$, Heikki Huhta ${ }^{4}$, Juulia Junno ${ }^{4}$, Tiina Erkinaro ${ }^{5}$,

5 Pasi Ohtonen $^{6}$, Mervi Haapsamo ${ }^{7}$, Ganesh Acharya ${ }^{1,8}$

6

7 Women's Health \& Perinatal Research Group, Department of Clinical Medicine, UiT-

8 The Arctic University of Norway, Tromsø, Norway (1),

9 Department of Obstetrics and Gynecology, Kuopio University Hospital and

10 University of Eastern Finland, Kuopio, Finland (2),

11 Department of Obstetrics and Gynecology, Helsinki University Hospital, Helsinki,

12 Finland (3),

13 Department of Obstetrics and Gynecology (4), Anaesthesiology (5) and Statistics (6),

14 Oulu University Hospital, Oulu, Finland.

15 Department of Obstetrics and Gynecology, Lapland Central Hospital, Finland (7).

16 Department of Clinical Science, Intervention and Technology (CLINTEC),

17 Karolinska Institutet, Stockholm, Sweden (8)

21 Address for correspondence:

22 Dr. Amar Bhide, MD, FRCOG

23 Fetal Medicine Unit

$244^{\text {th }}$ Floor, Lanesborough Wing

25 St. George's Hospital, Blackshaw Road

26 SW17 0QT

27 United Kingdom

28 Tel: +442087250080

29 Fax: +44 2087250079

30 e-mail: abhide@sgul.ac.uk

32 Running title: Hypoxemia and ventricular deformation in fetal sheep 


\section{Abstract}

We hypothesized that in near-term sheep fetuses hypoxemia changes

3 myocardial function that is reflected in altered ventricular deformation on speckle-

4 tracking echocardiography. Fetuses were instrumented in 21 pregnant sheep. After 4-

5 day recovery, fetal cardiac function was assessed by echocardiography at baseline,

6 after 30 and 120 minutes of induced fetal hypoxemia and following its reversal. Left

7 (LV) and right ventricular (RV) cardiac outputs, myocardial strains were measured.

8 Baseline mean (SD) LV and RV global longitudinal strains were $-18.7 \%$ (3.8) and -

$9 \quad 14.3 \%$ (5.3). Baseline RV global longitudinal and circumferential deformations were 10 less compared to $\operatorname{LV}(\mathrm{p}=0.016$ and $\mathrm{p}<0.005$ ). LV, but not RV global longitudinal 11 strain reduced $(\mathrm{p}=0.003)$ compared to baseline with hypoxemia. Circumferential and 12 radial strains did not show significant changes. In near-term sheep fetus, LV global 13 longitudinal and circumferential strains are more negative compared to RV. Acute 14 hypoxemia leads to LV rather than RV dysfunction as demonstrated by decreased 15 deformation.

16

\section{Word count: 148}

19 Keywords - Speckle tracking echocardiography; hypoxemia; sheep model 
Introduction -

Fetal cardiovascular protective response to moderate isocapnic hypoxemia involves chemoreflex, endocrine and local components. Acute fetal hypoxemia is associated with increased blood flow to the myocardium, brain and adrenal glands, but the fetal autonomic response to hypoxemia varies by gestational age (Iwamoto, et al. 1989). At 0.6-0.7 gestation in fetal sheep (87-102 days), the arterial blood pressure (BP) does not change significantly and fetal heart rate may remain unchanged or increase slightly (Iwamoto, et al. 1989), whereas at 0.9 gestation vagally mediated bradycardia and a rise of BP is observed (Giussani, et al. 1993). Hemodynamic changes related to acute and chronic hypoxemia in sheep fetuses have been well

11 described (Carter 2015, Jensen, et al. 1999, Rudolph 1985). Chronic hypoxemia 12 without acidemia does not affect the fetal cardiac output (Block, et al. 1990). Blood 13 flow to the placenta, carcass, kidney, and spleen are maintained with chronic 14 hypoxemia until fetal acidosis develops (Jensen, et al. 1999). We have reported that 15 acute hypoxemia in near-term fetal sheep leads to an increase in the pulmonary arterial vascular impedance, as well as an increase in the right ventricular cardiac output (Mäkikallio, et al. 2006). Peak myocardial velocities measured by tissue Doppler technique appear to decrease during hypoxemia/acidemia especially during the isovolumic periods of cardiac cycle (Acharya, et al. 2008). However, changes in myocardial strain that may occur during fetal hypoxemia have not been elucidated. Two-dimensional (2-D) strain imaging uses standard B-mode images and speckletracking for the evaluation of myocardial deformation. Lagrangian strain is defined as the instantaneous lengthening or shortening compared to the initial muscle fiber length, which, in the myocardium, is commonly determined by the end of diastole (D'Hooge, et al. 2000). The relative independence of the angle of ultrasound beam and direction of movement makes this technique less prone to errors. Speckle tracking echocardiography is still a research tool, and its value in clinical practice is being debated (Huang and Orde 2013, Orde, et al. 2016, Tanaka and Hirata 2016). This technique has been used to evaluate cardiac function in normal fetuses (Kapusta, et al. 2012), those of diabetic mothers (Kulkarni, et al. 2016), fetuses with twin to twin

31 transfusion syndrome and those with congenital diaphragmatic hernia (Van Mieghem, 32 et al. 2011). To our knowledge, response of fetal myocardium to hypoxemia has not 33 been evaluated using speckle-tracking echocardiography. 
The present experiment on near-term fetal sheep was designed to test the hypothesis that a decrease in fetal oxygenation leads to compensatory changes in the myocardial function that can be detected by 2-D speckle-tracking echocardiography.

4 Specifically, we asked two questions in this study: 1) are left and right ventricular 5 deformations similar in normoxemic conditions and 2) are their responses to prolonged hypoxemia different?

\section{Material and methods}

All experiments were performed in accordance with the 'European 10 Convention for the Protection of Vertebrate Animals used for Experimental and Other 11 Scientific Purposes' (Council of Europe 1986) and the European Union Directive ETS 12123 (1997). The Animal Care and Use Committee of the University of Oulu approved 13 the study protocol.

14 Data from 21 chronically instrumented pregnant sheep were used for this 15 report. Mean (SD) weight of the ewes and the fetuses was 53.9 (8.1) $\mathrm{kg}$ and 2401 (256) g, respectively.

Surgery was performed at 115-129 gestational days (term 145 days). Ewes were fasted overnight and pre-medicated with intramuscular ketamine $(2 \mathrm{mg} / \mathrm{kg})$ and midazolam $(0.2 \mathrm{mg} / \mathrm{kg})$. The maternal external jugular vein was cannulated and Ringer's lactate solution was infused at a rate of $200 \mathrm{ml} / \mathrm{h}$. General anesthesia was induced with intravenous Propofol (4-7 mg/kg) and maintained with Isoflurane (1.5$2.5 \%$ ) in an oxygen-air mixture delivered via an endotracheal tube. Intravenous boluses of fentanyl $(0.05-0.15 \mathrm{mg})$ were administered as required.

A laparotomy was performed under general anesthesia and endotracheal intubation. The fetal head and neck were delivered through a small uterine incision. Catheters were introduced in the internal jugular vein and the carotid artery to allow access to arterial and venous circulations, and to collect blood samples.

A small left lateral thoracotomy was performed at the level of $3^{\text {rd }}$ intercostal space and the ductus arteriosus was identified and dissected. A $4 \mathrm{~mm}$ ultrasonic transit-time flow probe was secured around the vessel and tunneled outside for the measurement of ductus arteriosus blood flow. Thoracotomy was closed. Electrocardiogram (ECG) leads were placed subcutaneously to obtain fetal ECG. A catheter was anchored to the fetal skin to measure intra amniotic pressure. After the replacement of amniotic fluid by $0.9 \%$ warm saline and closure of the surgical 
1 wounds, all catheters and probes were tunneled subcutaneously and exteriorized

2 through a small skin incision in the ewe's flank. Postoperative analgesia was provided

3 with a fentanyl patch $(50 \mathrm{mcg} / \mathrm{h})$ attached to the ewe's tail, with additional

4 intramuscular injections of fentanyl 1.5 to $2 \mathrm{mg} / \mathrm{kg}$ twice daily.

After a 4-day recovery, general anesthesia was induced again as described above. A 16-gauge polyurethane catheter was inserted into the maternal descending aorta through a femoral artery. The ewe was placed supine with a right lateral tilt and allowed to stabilize for $30 \mathrm{~min}$ before the baseline measurements. Thereafter, maternal and fetal hypoxemia was induced by replacing inhaled oxygen with medical air in the re-breathing circuit to reach maternal oxyhemoglobin saturation level of 75$80 \%$. Hypoxemia phase data were obtained at 30 minutes and 120 minutes after reaching desired maternal saturation level. After the data collection for the last hypoxemia phase was completed, oxygen was substituted, and re-breathing discontinued to allow recovery from hypoxemia, and recovery phase data was obtained 15 minutes after maternal normoxemia was established. Fetal heart rate was monitored with a cardiotachometer triggered from the arterial pressure waves. Fetal arterial blood pressure was referenced to amniotic fluid pressure. Fetal blood samples were obtained to measure the acid-base status, and blood gases at the end of each phase. At the end of the experiment, the animals were euthanized with an intravenous overdose $(1.0 \mathrm{mg} / \mathrm{kg})$ of pentobarbital sodium. Fetal weight was recorded.

Fetal echocardiography was performed using Vivid 7 ultrasound system (GE medical systems, Horten, Norway) with a $10-\mathrm{MHz}$ phased-array transducer to obtain 2-D gray-scale images with a high frame-rate. Cine-loop images of four-chamber view and short-axis view at the level of papillary muscles were obtained by a single investigator (JR). The imaging depth was 5 $-10 \mathrm{~cm}$ and the mechanical index (MI) and thermal index (TI) were kept below 1.5 and 1.0, respectively. Two stable welldefined consecutive cardiac cycles from each view were used for speckle tracking analysis. The scan-line digital data for these images were processed using acoustictracking software (EchoPAC, GE medical systems, Horten, Norway), allowing off-

31 line semi-automated analysis of speckle-based strain.

The off-line analysis was performed by a single operator (AB) who was blinded to the fetal arterial blood gas values and hemodynamic data. Endocardial 34 surface was manually traced at the end-systolic frame, and an automated tracking 
1 algorithm outlined the myocardium in successive frames throughout the cardiac cycle

2 (Figure 1). Tracking quality was verified automatically for each segment. Manual

3 adjustment of the region of interest was performed if necessary. Myocardial global

4 longitudinal strain was measured for left and the right ventricles on a four-chamber

5 view. These measurements were repeated in another cardiac cycle from the second

6 stored cine-loop of the same fetus. Mean of these two measurements were used for

7 data analysis. Interventricular septum was not excluded while measurement of the RV

8 global longitudinal strain was performed. Global circumferential and radial strains for

9 the left and the right ventricle (Hayabuchi, et al. 2015) were calculated from the short10 axis view at the level of the papillary muscles (Figure 2). An average of segmental

11 values was calculated to obtain global values.

Blood flow velocity waveforms were obtained at the level of aortic and pulmonary valves keeping the angle of insonation close to zero degrees (always $<15$ degrees), and the mean velocities were determined (mean velocity = time-velocity integral $\mathrm{x}$ heart rate). Inner diameters of the aortic and pulmonary valves were measured using a B-mode cine loop images keeping the insonation angle perpendicular to the vessels as far as possible (Kiserud, et al. 2006). An average of three measurements was used for calculating cardiac outputs. The left (LVCO) and the right ventricular cardiac outputs (RVCO) were computed separately as: cardiac output $(\mathrm{CO})=$ mean velocity $\times 3.14$ (diameter of the outflow tract $/ 2)^{2}$. The combined cardiac output (CCO) was calculated as the sum of LVCO and RVCO.

The pulmonary volume blood flow was calculated as the difference between the RVCO and the ductus arteriosus volume blood flow. Doppler blood flow velocity waveforms were obtained from the right pulmonary artery (RPA) as described previously (Rasanen, et al. 1996). Pulsatility index (PI) was calculated as: (peak systolic velocity - end-diastolic velocity)/time-averaged maximum velocity(Deane 2000) as a surrogate for pulmonary arterial vascular impedance.

Data were expressed as mean and standard deviation (SD) unless stated otherwise. Linear Mixed Model (LMM) was used for repeatedly measured data. If LMM showed a significant difference between measurement points $\left(\mathrm{P}_{\text {time }}<0.05\right)$, then a pairwise comparison between relevant points was performed. Paired samples t-test 
1 was used to compare LV and RV global longitudinal, circumferential and radial strains. Mean differences with 95\% confidence intervals (95\% CI) are presented for paired samples t-test. Statistical analyses were performed using SPSS (IBM Corp. Released 2011. IBM SPSS Statistics for Windows, Version 20.0. Armonk, NY: IBM Corp.) and SAS (version 9.3. SAS Institute Inc., Cary, NC, USA). Two-tailed p value $6<0.05$ was considered statistically significant.

\section{Results}

Maternal hypoxemia led to a significant reduction in fetal $\mathrm{pO}_{2}$, and during recovery phase it returned back to baseline level (Table 1). Fetal $\mathrm{pH}$ decreased significantly at 120-minute hypoxemia phase and remained significantly lower during recovery phase than at baseline. In addition, fetal lactate level was significantly higher during hypoxemia and recovery phases than at baseline. Fetal $\mathrm{pCO}_{2}$ did not change during the experiment. Hypoxemia decreased fetal arterial blood pressures significantly (Table 1). Fetal heart rate was significantly lower at the recovery phase as compared to baseline and hypoxemia phases. During hypoxemia, there was a significant increase in fetal RPA PI values and a decrease in LVCO. Pulmonary blood flow decreased with hypoxemia compared to the baseline, but the reduction did not reach statistical significance. Fetal RVCO and CCO remained stable during the entire experiment (Table 1).

\section{2-D strain data}

Ultrasound recordings were obtained at a mean frame rate of 167 (Range: 126235) frames/sec. At baseline, there was significantly more deformation in the LV global longitudinal $(\mathrm{p}=0.016)$ and circumferential $(\mathrm{p}<0.005)$ strains than in the corresponding parameters of the RV (Table 2). Hypoxemia at 30 and 120 minutes led to a significant reduction (less deformation) in the global longitudinal strain of the $\mathrm{LV}$, while the global circumferential and radial strains were not affected by fetal hypoxemia (Table 2, Figure 3). During the recovery period, LV global longitudinal strain returned back to baseline level. Right ventricular global longitudinal, circumferential and radial strains did not change statistically significantly. Baseline left ventricular strain rate was significantly higher than the right $(p=0.003)$. There were no significant changes in left or right ventricular global longitudinal strain rates 


\section{Discussion}

The present study was designed to investigate the effect of fetal hypoxemia on

3 LV and RV strain formation. The experiments were done in fetal sheep at 0.8 4 gestation that corresponds to approximately 30-32 weeks gestation of human 5 pregnancy. Blood gas values demonstrated that after 30 minutes of hypo-oxygenation 6 the fetuses were hypoxemic without any significant metabolic component, but 7 prolonged hypoxemia (120 minutes) led to significant fetal metabolic acidemia. In the 8 recovery phase, fetal oxygenation returned back to baseline level, but there was still 9 significant metabolic acidemia. We found that at baseline there was more global 10 longitudinal and circumferential deformation (strain) in the LV than in the RV. Fetal 11 hypoxemia was associated with reduced LV global longitudinal strain that returned 12 back to baseline level when fetal normoxemia was restored, even though the fetus still 13 had a significant metabolic acidemia. Fetal hypoxemia, even with metabolic 14 academia, had no effect on RV strains.

\section{5}

A reduction in the LV global longitudinal deformation with hypoxemia may be a result of reduced LV preload, direct LV myocardial dysfunction or a combination of the two. It has been shown that pulmonary circulation is sensitive to fetal oxygenation during the last trimester of pregnancy (Rasanen, et al. 1996), and that hypoxemia leads to pulmonary vasoconstriction (Arraut, et al. 2013). Indeed, in the current experiment RPA PI values increased significantly with hypoxemia suggesting that impedance to pulmonary blood flow increased during hypoxemia, although the reduction in the estimated pulmonary volume blood flow was not statistically significant. It has been shown in a near-term sheep model of acute ductus arteriosus occlusion that the fetus is unable to increase volume blood flow across the foramen ovale (Tulzer, et al. 1991), thus the reduction in the LVCO is most likely a consequence of a drop in pulmonary volume blood flow leading to a decrease in LV preload. It has been shown in human fetuses that global longitudinal strain is similar in both ventricles at 20-24 weeks of gestation (Kapusta, et al. 2012). Later in pregnancy LV global longitudinal strain does not change, however, corresponding RV strain or deformation decreases. This is explained by an increase in the RV preload. If the change in preload would be the major factor in the strain formation, we should have observed an opposite finding in the LV global longitudinal strain. Therefore, our 
1 results indicate that the direct effect of hypoxemia on intrinsic contractile properties

2 of the LV is likely responsible for decreased global longitudinal strain.

Fetal global LV longitudinal deformation already decreased at 30-minute hypoxemia phase, when significant metabolic acidemia had not yet developed. At 120-minute hypoxemia phase fetal $\mathrm{pO}_{2}$ was comparable to 30-minute hypoxemia phase, however, a significant metabolic acidemia had developed between these two time points. Interestingly, we found no further deterioration in any of the strain parameters. We have previously reported that fetal LV is more susceptible to hypoxemia as compared to fetal RV. However, in that study, fetal cardiac function and hemodynamics were assessed by tissue Doppler and pulsed Doppler imaging, rather than speckle tracking The findings of this study corroborate our previous observations. We have also found that the fetal LV myocardial performance index significantly worsens with hypoxemia (Bhide, et al. 2016), which also supports the findings of this study. At recovery phase, when fetal oxygenation was returned back to baseline conditions, the LV global longitudinal strain was similar to baseline values, even though fetuses were still suffering from significant metabolic acidemia. Furthermore, LVCO, RVCO or CCO did not show significant changes with progressive metabolic acidemia. This shows that the fetal myocardial function was not further deteriorated despite worsening metabolic acidemia. Our results suggest that LV function appears to be more sensitive to oxygenation than metabolic acidosis. Experimental intravenous infusion of lactic acid to sheep fetuses led to reduction in fetal $\mathrm{pH}$, increase in the heart rate but no change in blood pressure (Hohimer and Bissonnette 1991). This also suggests that lactic acid does not influence cardiac function.

Di Salvo et al (Di Salvo, et al. 2005) were the first to describe fetal LV and $\mathrm{RV}$ function using ultrasound based strain and strain rate imaging. They used myocardial color Doppler imaging for quantification of strain. Doppler technology is known to be angle dependent, which speckle tracking can eliminate (Biswas, et al. 2013). There are several software programs to assess myocardial deformation using speckle tracking. However, they are not necessarily comparable. The velocity vector imaging mainly tracks myocardial motion in a narrow area just underneath the endocardium. In contrast, the EchoPAC automated functional imaging software tracks 
1 myocardial deformation in a relatively wider area, specified by the operator (Biswas,

2 et al. 2013).

Strengths and weaknesses

At least 60-110 frames per second are recommended when imaging the adult heart (Mondillo, et al. 2011), and even higher rates are desirable to provide enough frames per heart beat in the fetus (Matsui, et al. 2011). We studied the fetus at a mean frame rate of $167 \mathrm{~Hz}$, and this is likely to have led to reliable results. The surgical procedures may constitute a significant stress on the sheep fetuses, and it may be argued that the conditions are quite different from human fetuses exposed to hypoxemia. Normal arterial blood gas values at the baseline stage suggest conditions close to physiologic circulatory state (Acharya, et al. 2004). The study was carried out in a narrow gestational age window of 115-129 days, and may limit the validity and significance outside this time period. Extrapolation of these results to human pregnancy should be done cautiously. The sheep model has been extensively used for research in fetal hemodynamics, and the myocardial strain curves are similar in normal ovine and human pregnancy. We did not monitor cerebral blood flow during the experiment and it could be argued that the reduction in LV global longitudinal strain could just reflect a drop in cerebral vascular resistance during hypoxemia. Indeed, carotid artery blood pressure decreased during hypoxemia. Furthermore, it has been shown that carotid artery volume blood flow increases from about $85 \mathrm{ml} / \mathrm{min}$ (normoxemia) to about $95-100 \mathrm{ml} / \mathrm{min}$ during isocapnic hypoxemia (Bennet, et al. 1998). We can estimate that there was about $24 \%$ reduction in the carotid artery vascular resistance during hypoxemia. However, based on these estimations, over $80 \%$ of LVCO bypasses brain circulation during prolonged hypoxemia and is affected by lower body vascular resistance. Thus, we believe that reduced carotid artery vascular resistance is not the main determinant of reduced LV global longitudinal strain during hypoxemia.

\section{Conclusion}

We have shown that hypoxemia leads to changes in fetal cardiac function that is reflected in altered ventricular deformation on speckle-tracking echocardiography. At a gestational age equivalent to 0.8 term, the global longitudinal and circumferential strains are less negative in the RV as compared to the LV. Fetus responds to acute 
1 reversed by reversal of hypoxemia. This recovery of LV function is seen even in the 2 presence of metabolic acidemia.

3

4 Acknowledgement: This study was funded by the Regional Health Authority of 5 Northern Norway.

6

7 


\section{References}

2 Acharya G, Erkinaro T, Makikallio K, Lappalainen T, Rasanen J. Relationships among Doppler-derived umbilical artery absolute velocities, cardiac function, and placental volume blood flow and resistance in fetal sheep. American journal of physiology. Heart and circulatory physiology 2004; 286:H1266-72.

Acharya G, Rasanen J, Makikallio K, Erkinaro T, Kavasmaa T, Haapsamo M, Mertens L, Huhta JC. Metabolic acidosis decreases fetal myocardial isovolumic velocities in a chronic sheep model of increased placental vascular resistance. American journal of physiology. Heart and circulatory physiology 2008; 294:H498-504.

Arraut AM, Frias AE, Hobbs TR, McEvoy C, Spindel ER, Rasanen J. Fetal pulmonary arterial vascular impedance reflects changes in fetal oxygenation at near-term gestation in a nonhuman primate model. Reprod Sci 2013; 20:33-8.

Bennet L, Peebles DM, Edwards AD, Rios A, Hanson MA. The cerebral hemodynamic response to asphyxia and hypoxia in the near-term fetal sheep as measured by near infrared spectroscopy. Pediatric research 1998; 44:951-7.

Bhide A, Vuolteenaho O, Haapsamo M, Erkinaro T, Rasanen J, Acharya G. Effect of Hypoxemia with or without Increased Placental Vascular Resistance on Fetal Left and Right Ventricular Myocardial Performance Index in Chronically Instrumented Sheep. Ultrasound in medicine \& biology 2016; 42:2589-98.

Biswas M, Sudhakar S, Nanda NC, Buckberg G, Pradhan M, Roomi AU, Gorissen W, Houle H. Two- and three-dimensional speckle tracking echocardiography: clinical applications and future directions. Echocardiography 2013; 30:88-105.

Block BS, Schlafer DH, Wentworth RA, Kreitzer LA, Nathanielsz PW. Intrauterine asphyxia and the breakdown of physiologic circulatory compensation in fetal sheep. American journal of obstetrics and gynecology 1990; 162:1325-31.

Carter AM. Placental Gas Exchange and the Oxygen Supply to the Fetus. Compr Physiol 2015; 5:1381-403.

D'Hooge J, Heimdal A, Jamal F, Kukulski T, Bijnens B, Rademakers F, Hatle L, Suetens P, Sutherland GR. Regional strain and strain rate measurements by cardiac ultrasound: principles, implementation and limitations. European journal of echocardiography : the journal of the Working Group on Echocardiography of the European Society of Cardiology 2000; 1:154-70. 
1 Deane C. Doppler Ultrasound:priciples and practice, In: Niclaides K, Rizzo G, Hecher K., ed. Placental and fetal Doppler. London: The Parthenon Publishing Group, 2000. 22.

Di Salvo G, Russo MG, Paladini D, Pacileo G, Felicetti M, Ricci C, Cardaropoli D, Palma M, Caso P, Calabro R. Quantification of regional left and right ventricular longitudinal function in 75 normal fetuses using ultrasound-based strain rate and strain imaging. Ultrasound in medicine \& biology 2005; 31:1159-62.

Giussani DA, Spencer JA, Moore PJ, Bennet L, Hanson MA. Afferent and efferent components of the cardiovascular reflex responses to acute hypoxia in term fetal sheep. The Journal of physiology 1993; 461:431-49.

Hayabuchi Y, Sakata M, Kagami S. Right ventricular myocardial deformation patterns in children with congenital heart disease associated with right ventricular pressure overload. Eur Heart J Cardiovasc Imaging 2015; 16:8909.

Hohimer AR, Bissonnette JM. Vascular lactic acid infusions do not alter the incidence of fetal breathing movements or their inhibition by acute hypoxemia. Pediatric research 1991; 29:483-6.

Huang SJ, Orde S. From speckle tracking echocardiography to torsion: research tool today, clinical practice tomorrow. Curr Opin Crit Care 2013; 19:250-7.

Iwamoto HS, Kaufman T, Keil LC, Rudolph AM. Responses to acute hypoxemia in fetal sheep at 0.6-0.7 gestation. The American journal of physiology 1989; 256:H613-20.

Jensen A, Garnier Y, Berger R. Dynamics of fetal circulatory responses to hypoxia and asphyxia. European journal of obstetrics, gynecology, and reproductive biology 1999; 84:155-72.

Kapusta L, Mainzer G, Weiner Z, Deutsch L, Khoury A, Haddad S, Lorber A. Second trimester ultrasound: reference values for two-dimensional speckle trackingderived longitudinal strain, strain rate and time to peak deformation of the fetal heart. Journal of the American Society of Echocardiography : official publication of the American Society of Echocardiography 2012; 25:1333-41.

Kiserud T, Ebbing C, Kessler J, Rasmussen S. Fetal cardiac output, distribution to the placenta and impact of placental compromise. Ultrasound in obstetrics \& 
gynecology : the official journal of the International Society of Ultrasound in Obstetrics and Gynecology 2006; 28:126-36.

Kulkarni A, Li L, Craft M, Nanda M, Lorenzo JM, Danford D, Kutty S. Fetal Myocardial Deformation in Maternal Diabetes Mellitus and Obesity. Ultrasound in obstetrics \& gynecology : the official journal of the International Society of Ultrasound in Obstetrics and Gynecology 2016.

Mäkikallio K, Erkinaro T, Niemi N, Kavasmaa T, Acharya G, Päkkilä M, Räsänen J. Fetal oxygenation and Doppler ultrasonography of cardiovascular hemodynamics in a chronic near-term sheep model. American journal of obstetrics and gynecology 2006; 194:542-50.

Matsui H, Germanakis I, Kulinskaya E, Gardiner HM. Temporal and spatial performance of vector velocity imaging in the human fetal heart. Ultrasound in obstetrics \& gynecology : the official journal of the International Society of Ultrasound in Obstetrics and Gynecology 2011; 37:150-7.

Mondillo S, Galderisi M, Mele D, Cameli M, Lomoriello VS, Zacà V, Ballo P, D'Andrea A, Muraru D, Losi M, Agricola E, D'Errico A, Buralli S, Sciomer S, Nistri S, Badano L, Echocardiography Study Group Of The Italian Society Of Cardiology (Rome Ia. Speckle-tracking echocardiography: a new technique for assessing myocardial function. Journal of ultrasound in medicine : official journal of the American Institute of Ultrasound in Medicine 2011; 30:71-83.

Orde S, Huang SJ, McLean AS. Speckle tracking echocardiography in the critically ill: enticing research with minimal clinical practicality or the answer to noninvasive cardiac assessment? Anaesth Intensive Care 2016; 44:542-51.

Rasanen J, Wood DC, Weiner S, Ludomirski A, Huhta JC. Role of the pulmonary circulation in the distribution of human fetal cardiac output during the second half of pregnancy. Circulation 1996; 94:1068-73.

Rudolph AM. Distribution and regulation of blood flow in the fetal and neonatal lamb. Circ Res 1985; 57:811-21.

Tanaka H, Hirata K. Is speckle tracking actually helpful for cardiac resynchronization therapy? J Echocardiogr 2016; 14:53-60.

Tulzer G, Gudmundsson S, Rotondo KM, Wood DC, Yoon GY, Huhta JC. Acute fetal ductal occlusion in lambs. American journal of obstetrics and gynecology $1991 ; 165: 775-8$. 
1 Van Mieghem T, Deprest J, Verhaeghe J. Fetal and maternal hemodynamics in pregnancy: new insights in the cardiovascular adaptation to uncomplicated pregnancy, twin-to-twin transfusion syndrome and congenital diaphragmatic hernia. Facts Views Vis Obgyn 2011; 3:205-13.

5

6 


\section{$1 \quad$ Legend to figures}

2 Figure 1. Automated tracking algorithm outlining the myocardium and calculation of 3 global strain and strain rate using Echopac software.

4

5 Figure 2. Automated tracking algorithm outlining the myocardium and calculation of 6 right ventricular global circumferential strain using Echopac software.

7

8 Figure 3. Global left (solid lines) and right ventricular (dotted line) longitudinal strain 9 with hypoxemia and recovery 
Table 1. Fetal parameters during the experiment

\begin{tabular}{|c|c|c|c|c|c|}
\hline Parameter & Baseline & $\begin{array}{c}\text { Hypoxemia } \\
\text { (30 min) }\end{array}$ & $\begin{array}{c}\text { Hypoxemia } \\
\text { (120 min) }\end{array}$ & Recovery & $\mathbf{P}_{\text {time }}$ \\
\hline $\begin{array}{l}\text { Fetal heart rate } \\
(\mathrm{BPM})\end{array}$ & $169(38)$ & $166(26)$ & $170(24)$ & $136(16)$ & 0.004 \\
\hline $\begin{array}{l}\text { Fetal SBP (mm } \\
\mathrm{Hg})\end{array}$ & $60(10.3)$ & $52(8.5)$ & $54(7.4)$ & $56(8.7)$ & 0.0008 \\
\hline $\begin{array}{l}\text { Fetal DBP (mm } \\
\mathrm{Hg})\end{array}$ & $40(7.5)$ & $35(8.8)$ & $36(7.3)$ & $37(8.4)$ & 0.034 \\
\hline $\begin{array}{l}\text { Fetal MAP (mm } \\
\mathrm{Hg})\end{array}$ & $49(10.7)$ & $43(11.2)$ & $47(10.9)$ & $48(10.3)$ & 0.050 \\
\hline Fetal pO2 $(\mathrm{kPa})$ & $2.79(0.32)$ & $1.59(0.40)$ & $1.49(0.16)$ & $2.80(0.41)$ & $<0.0001$ \\
\hline Fetal pCO2 $(\mathrm{kPa})$ & $6.51(1.06)$ & $6.68(0.48)$ & $7.05(0.99)$ & $6.81(0.48)$ & 0.56 \\
\hline Fetal $\mathrm{pH}$ & $7.32(0.05)$ & $7.30(0.04)$ & $7.14(0.12)$ & $7.17(0.06)$ & $<0.0001$ \\
\hline Fetal BE (mM/ml) & $-1.39(2.35)$ & $-2.05(2.92)$ & $-10.70(6.07)$ & $-9.63(3.25)$ & $<0.0001$ \\
\hline $\begin{array}{l}\text { Fetal lactate } \\
(\mathrm{mM} / \mathrm{ml})\end{array}$ & $2.42(1.63)$ & $4.10(1.84)$ & $10.17(3.94)$ & $9.91(4.20)$ & $<0.0001$ \\
\hline $\begin{array}{l}\text { Left ventricular } \\
\text { output (LVCO) } \\
\text { ml/min }\end{array}$ & $644(198)$ & $501(122)$ & $545(123)$ & $548(157)$ & 0.010 \\
\hline $\begin{array}{l}\text { Right ventricular } \\
\text { output (RVCO) } \\
\underline{\mathrm{ml} / \mathrm{min}}\end{array}$ & $644(159)$ & $638(229)$ & $651(179)$ & $619(147)$ & 0.60 \\
\hline $\begin{array}{l}\text { Combined cardiac } \\
\text { output }(\mathrm{CCO}) \\
\underline{\mathrm{ml} / \mathrm{min}}\end{array}$ & $1288(294)$ & $1125(246)$ & $1184(240)$ & $1158(229)$ & 0.19 \\
\hline $\begin{array}{l}\text { Right pulmonary } \\
\text { artery PI }\end{array}$ & $12.54(11.75)$ & $66.97(26.88)$ & $57.08(23.94)$ & $69.42(56.93)$ & $0.006 * *$ \\
\hline $\begin{array}{l}\text { Pulmonary flow } \\
\text { (ml/min) }\end{array}$ & 467 (177) & $311(127)$ & $303(204)$ & $299(179)$ & 0.089 \\
\hline
\end{tabular}


$\mathrm{BPM}=$ Beats per minute, $\mathrm{MAP}=$ Mean arterial pressure $\mathrm{SBP}=$ Systolic blood pressure, $\mathrm{DBP}$ $=$ Diastolic blood pressure, $\mathrm{BE}=$ Base excess, $\mathrm{PI}=$ pulsatility Index

FHR significantly different with recovery as compared to all other phases.

Significant difference between baseline compared to 30 min hypoxemia as well as baseline compared to 120 min hypoxemia for SBP and DBP.

Significant difference between baseline compared to 30 and 120 min hypoxemia for pO2.

Significant difference between baseline and all the other three phases for $\mathrm{pH}$, LVCO, BE, lactate.

**RPA PI was log transformed. Significant difference between baseline compared to 30,120 min hypoxemia and recovery for Right pulmonary artery PI. 
Table 2. 2-D strain data using speckle tracking echocardiography

2

\begin{tabular}{|c|c|c|c|c|c|c|}
\hline Parameter & Baseline & $\begin{array}{l}\text { Hypoxemia } \\
\text { (30 min) }\end{array}$ & $\begin{array}{l}\text { Hypoxemia } \\
\text { (120 min) }\end{array}$ & Recovery & $\mathbf{P}_{\text {time }}$ & Formatted Table \\
\hline $\begin{array}{l}\text { LV global longitudinal } \\
\operatorname{strain}(\%)\end{array}$ & $\begin{array}{l}-18.7 \\
(3.8)\end{array}$ & $\begin{array}{l}-13.9 \\
(3.3)\end{array}$ & $\begin{array}{l}-15.4 \\
(4.3)\end{array}$ & $\begin{array}{l}-17.8 \\
(2.9)\end{array}$ & $0.005 *$ & \\
\hline $\begin{array}{l}\text { LV global longitudinal } \\
\text { strain rate }(1 / \mathrm{s})\end{array}$ & $\begin{array}{l}\underline{-2.50} \\
\underline{(0.55)} \\
\end{array}$ & $\begin{array}{l}\underline{-2.58} \\
\underline{(0.64)} \\
\end{array}$ & $\begin{array}{l}\underline{-2.67} \\
\underline{(0.86)} \\
\end{array}$ & $\begin{array}{l}\underline{-2.70} \\
\underline{(0.79)} \\
\end{array}$ & $0 \div 91$ & $\begin{array}{l}\text { Formatted: Font: Not Bold } \\
\text { Formatted: Left }\end{array}$ \\
\hline $\begin{array}{l}\text { LV circumferential } \\
\text { strain }(\%)\end{array}$ & $\begin{array}{l}-21.0 \\
(5.9)\end{array}$ & $\begin{array}{l}-18.5 \\
(6.7)\end{array}$ & $\begin{array}{l}-19.3 \\
(6.6)\end{array}$ & $\begin{array}{l}-19.3 \\
(5.7)\end{array}$ & $\theta .69$ & Formatted Table \\
\hline LV Radial strain $(\%)$ & $\begin{array}{l}17.1 \\
(7.0)\end{array}$ & $\begin{array}{l}12.8 \\
(6.3)\end{array}$ & $\begin{array}{l}14.5 \\
(5.4)\end{array}$ & $\begin{array}{l}13.7 \\
(4.7)\end{array}$ & 0.31 & \\
\hline $\begin{array}{l}\text { RV Global longitudinal } \\
\operatorname{strain}(\%)\end{array}$ & $\begin{array}{l}-14.3 \\
(5.4)\end{array}$ & $\begin{array}{l}-14.8 \\
(2.7)\end{array}$ & $\begin{array}{l}-14.7 \\
(3.9)\end{array}$ & $\begin{array}{l}-15.3 \\
(2.2)\end{array}$ & $>0.9$ & \\
\hline $\begin{array}{l}\text { RV global longitudinal } \\
\underline{\text { strain rate }(1 / \mathrm{s})}\end{array}$ & $\begin{array}{l}\frac{-2.00}{(0.48)} \\
\end{array}$ & $\begin{array}{l}\frac{-2.27}{(0.50)} \\
\end{array}$ & $\begin{array}{l}\underline{-2.11} \\
\underline{(0.86)} \\
\end{array}$ & $\begin{array}{l}\underline{-2.07} \\
\underline{(0.37)} \\
\end{array}$ & $\underline{0.57}$ & \\
\hline $\begin{array}{l}\text { RV Circumferential } \\
\text { strain }(\%)\end{array}$ & $\begin{array}{l}-11.1 \\
(5.3)\end{array}$ & $\begin{array}{l}-13.6 \\
(5.6)\end{array}$ & $\begin{array}{l}-11.7 \\
(6.3)\end{array}$ & $\begin{array}{l}-11.7 \\
(4.6)\end{array}$ & $\theta .20$ & Formatted Table \\
\hline RV Radial strain (\%) & $\begin{array}{l}14.3 \\
(4.8)\end{array}$ & $\begin{array}{l}10.8 \\
(2.0)\end{array}$ & $\begin{array}{l}10.3 \\
(5.1)\end{array}$ & $\begin{array}{l}14.1 \\
(4.8)\end{array}$ & 0.15 & \\
\hline
\end{tabular}

$4 * \mathrm{p}=0.0011$ between baseline and 30 minute hypoxemia, $\mathrm{p}=0.026$ between baseline

5 and $120 \mathrm{~min}$ hypoxemia and $\mathrm{p}=0.013$ between 30 min hypoxemia and recovery.

$6 \quad \mathrm{p}=0.016$ between baseline left and right ventricular baseline global longitudinal

7 strain,

$8 \quad \mathrm{p}<0.005$ between baseline left and right ventricular baseline global circumferential

9 strain, $p=0.003$ between baseline left and right ventricular global longitudinal strain

10 rate

11

12

13

14

15 
Click here to download high resolution image
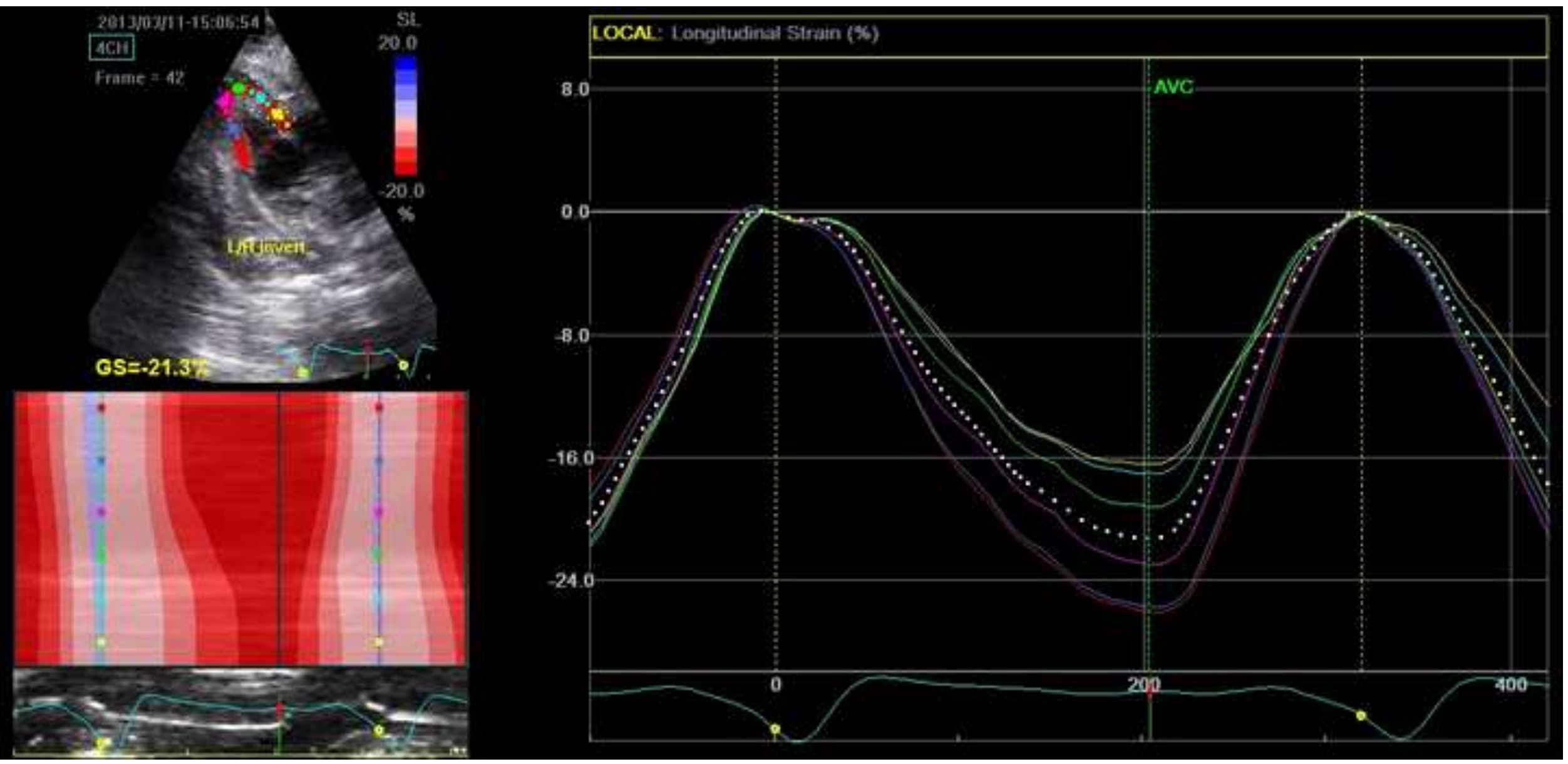
Click here to download high resolution image

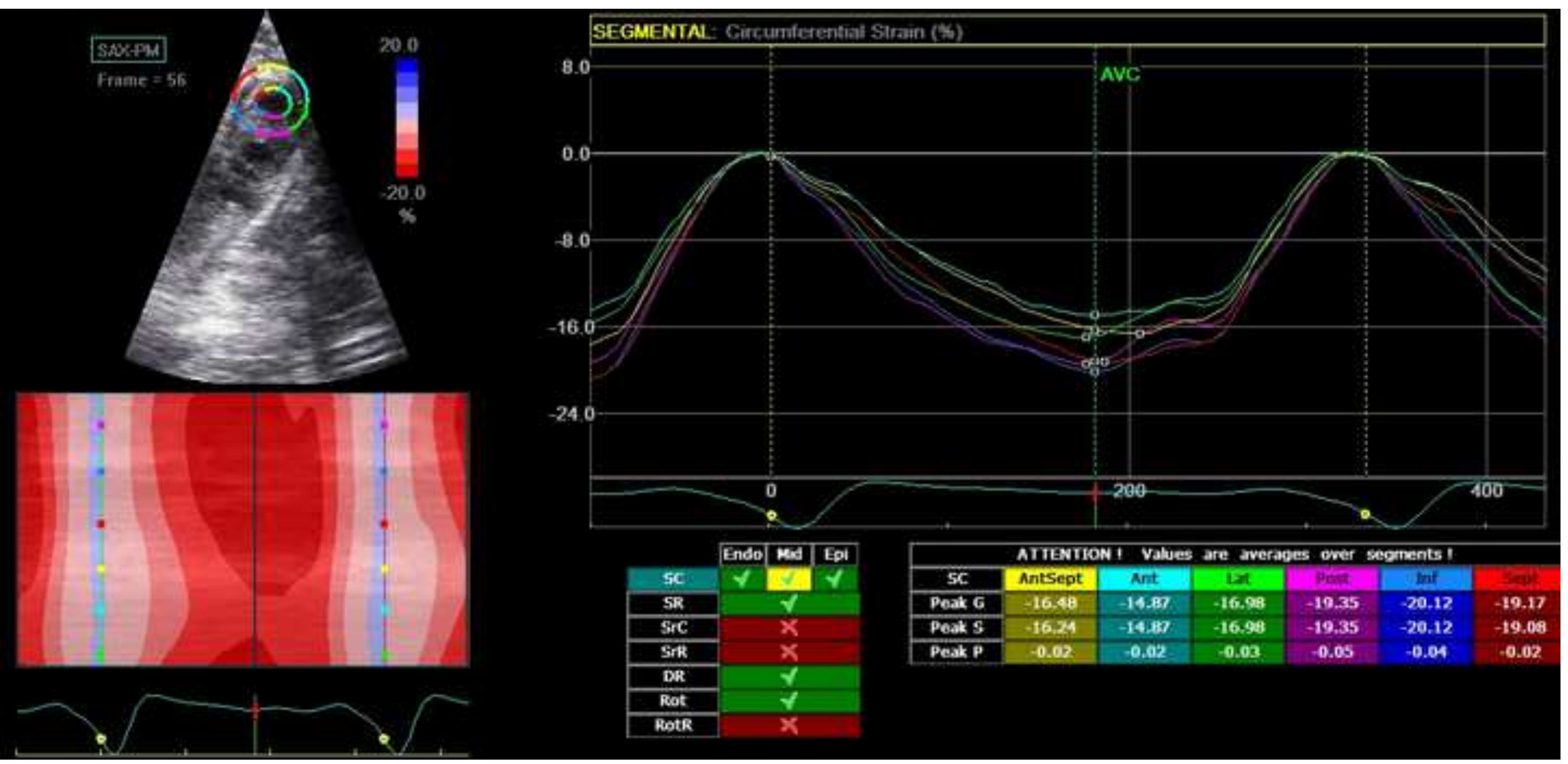

\section{SASEPM}




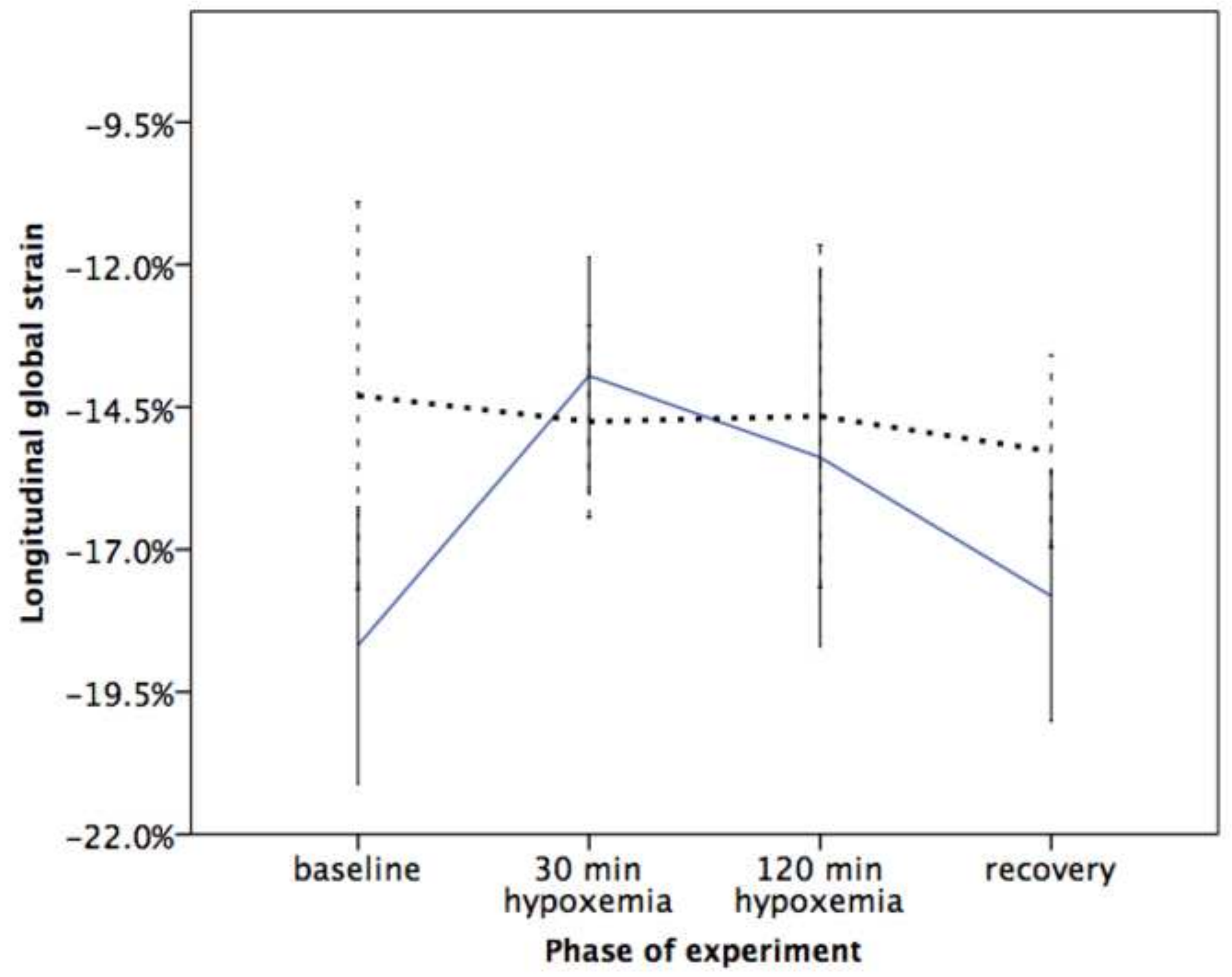

